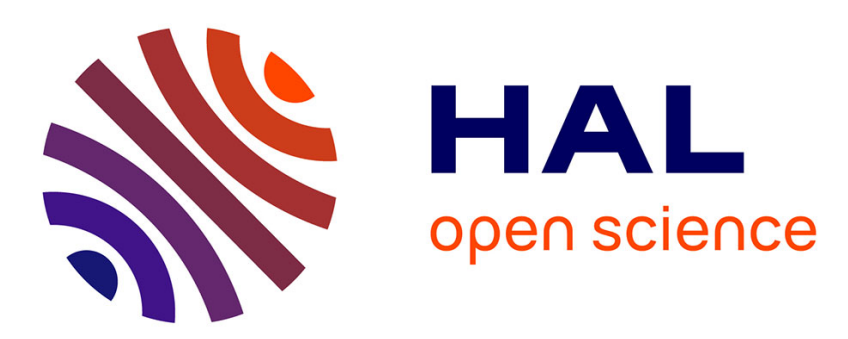

\title{
Which factors influence the psychological distress among relatives of patients with chronic functional psychoses? An exploratory study in a community mental health care setting
}

Ines Nitsche, Rainer Koch, Thomas W. Kallert

\section{To cite this version:}

Ines Nitsche, Rainer Koch, Thomas W. Kallert. Which factors influence the psychological distress among relatives of patients with chronic functional psychoses? An exploratory study in a community mental health care setting. Journal of Public Health, 2009, 18 (2), pp.105-117. 10.1007/s10389-0090292-3 . hal-00535296

\author{
HAL Id: hal-00535296 \\ https://hal.science/hal-00535296
}

Submitted on 11 Nov 2010

HAL is a multi-disciplinary open access archive for the deposit and dissemination of scientific research documents, whether they are published or not. The documents may come from teaching and research institutions in France or abroad, or from public or private research centers.
L'archive ouverte pluridisciplinaire HAL, est destinée au dépôt et à la diffusion de documents scientifiques de niveau recherche, publiés ou non, émanant des établissements d'enseignement et de recherche français ou étrangers, des laboratoires publics ou privés. 


\title{
Which factors influence the psychological distress among relatives of patients with chronic functional psychoses? An exploratory study in a community mental health care setting
}

\author{
Ines Nitsche • Rainer Koch • Thomas W. Kallert
}

Received: 9 February 2009 / Accepted: 23 September 2009 / Published online: 29 October 2009

(C) Springer-Verlag 2009

\begin{abstract}
Aim This research aimed to assess the contribution of the five core areas of the transactional stress model to the relatives' psychological distress (PD) when informally taking care of patients with functional psychoses treated in community mental health care.

Subjects and methods Cross-sectional data from 163 relatives were collected in interviews, while data on 158 patients were collected by analyzing clinical charts. The following areas were assessed: socio-demographic and illness-related features of the patients, socio-demographic features of the relatives (environmental variables); sense of coherence, mastery, causal attributions and opinions of relatives about mental disorders (person variables); interpersonal problems with the patients as well as the
\end{abstract}

\section{Nitsche $\cdot$ T. W. Kallert}

Department of Psychiatry and Psychotherapy, University Hospital

Carl Gustav Carus, Dresden University of Technology,

Fetscherstraße 74

01307 Dresden, Germany

R. Koch

Institute of Medical Information Technology and Biometrics,

Dresden University of Technology,

Löscherstraße 26,

01307 Dresden, Germany

T. W. Kallert $(\bowtie)$

Department of Psychiatry, Psychosomatic Medicine and

Psychotherapy, Park Hospital Leipzig,

Morawitzstraße 2,

04289 Leipzig, Germany

e-mail: thomas.kallert@parkkrankenhaus-leipzig.de

T. W. Kallert

Soteria Hospital Leipzig,

Morawitzstraße 4

04289 Leipzig, Germany assessment of their symptoms by the relatives themselves (primary appraisal); support received, critical life events and burden of relatives caused by their own illnesses (secondary appraisal); control behavior and efforts of relatives to engage the patients in activities (coping). PD was assessed with the 12-item version of the General Health Questionnaire. Bi-variate correlation analysis and a multiple linear regression model were the main test statistical approaches.

Results Correlation analysis showed that differences between diagnostic groups referred to primary and secondary appraisal processes, in particular. Results of the statistical model provided evidence for the importance of primary appraisal and person variables for influencing PD, and for the lack of importance of coping and environmental variables.

Conclusion The study enhanced the validity of the transactional stress model to demonstrate the influence of salutogenetic concepts such as sense of coherence.

Keywords Psychological distress · Relatives · Schizophrenic and affective disorders $\cdot$ Stress model . Appraisal processes

\section{Introduction}

Stress research has developed from stimulus- and reactionorientated theories to transactional models focusing on the transaction between people and their external environment. In this process, focus has shifted from a consideration of all possible burdening factors to physiological and psychological reactions of the individual and, finally, to the interaction between these components. Meanwhile, it is undisputed that objectively burdening stressors such as the mental disorder of 
a close reference person do not influence the well-being of relatives in a linear or direct way. This process is in many ways influenced by moderating or mediating variables like social support and coping (Pearlin et al. 1981) or help-seeking behavior and interpersonal problems between relatives and patients (Schene et al. 1998).

The stress-appraisal-coping paradigm (Lazarus and Folkman 1987) is a highly influential model in this field and provides the theoretical basis for the current study. At its core, this model demonstrates that the potential stressor repeatedly undergoes two individual appraisal processes. Primary appraisal refers to the cognitive processes of evaluating the significance of a burdening situation for an individual's wellbeing. If the results of this evaluation are positive, secondary appraisal refers to the person's judgments concerning availability and effectiveness of coping resources and options. Appraisal processes are continuously influenced by environmental variables (e.g., social situation, severity of the event) and person variables (e.g., personal commitments, goal hierarchies). Further, the model proposes that one's coping abilities mediate the stress response and are amenable to change, thus allowing stress to be controllable.

Research on the burden of relatives of people with mental disorders has considered the problem of intermediate factors that lead finally to psychological distress (PD). PD is defined as individual impairment of mental well-being caused by a specific stressor (Rider 2004). Several studies have demonstrated that objective illness-related features of the patients, such as duration of illness and number of hospitalizations, or expert assessments of the severity of psychopathological symptoms had little or no influence on the relatives' PD. This is also true for socio-demographic features of the patients and the relatives as well (e.g., Harvey et al. 2001; Jungbauer 2005; Provencher et al. 2003). Only a few research groups have provided evidence supporting the importance of the subjective evaluation of the situation. Struening et al. (1995) showed that low self-esteem and mastery (representing the general control belief of persons) are significant predictors for depressive symptoms of relatives. In addition, Boye et al. (2001) could demonstrate that external locus of control is a predictor for long-term distress. The number of such studies is still insufficient, however, and most have only interviewed relatives of patients with schizophrenic disorders. In consideration of the prevalence of patients with chronic affective disorders (e.g., Jacobi et al. 2004) and the increasing evidence on the burden of relatives when informally taking care of patients with recurrent depressive and bipolar disorders (e.g., Jenkins and Schumacher 1999; Mueser et al. 1996; Perlick et al. 1999; Schmid et al. 2007), there is a clear need for such research in these groups of relatives.

Against this background, the current study is designed to consider all five areas of variables from the transactional stress model of Lazarus and Folkman, and to explore their suitability as factors influencing PD. Furthermore, three groups of relatives supporting patients with different chronic mental disorders (schizophrenic, recurrent depressive and bipolar disorders) were assessed. The patients were treated in a community mental health care setting. Providing care was thus integrated in the everyday life duties of the relatives.

In detail, the study and this paper examine the following hypotheses:

(1) Given the exploratory character of the study and the lack of standardization referring to individual variables and to adequate instruments (Provencher et al. 2000) within stress-appraisal-coping research, at least one variable from each of the five core areas of the transactional stress model (environmental and person variables, primary and secondary appraisal, coping) should show a statistically significant correlation with PD. Because of the generalizability of the model, this result should appear in all three groups of relatives.

(2) Within the set of all variables, primary and secondary appraisal processes should appear as most important for influencing PD; person variables should also be of major importance, and environmental variables and coping should be only of minor importance for influencing PD. Appraisal processes determine whether the mental disorder is evaluated as stress-relevant and difficult to cope with. Traits, opinions and attributions of relatives could mediate the appraisal processes. The relationship of these mediating processes to the critical situation is not as concrete as the appraisal processes, however. Objective environmental variables might gain significance for the outcome only after they have been subjectively evaluated by the relative. Coping follows appraisal processes in the assessed stress model and is thus substantially influenced by these processes.

\section{Methods}

Data collection and features of the study samples

As approved by the ethics committee of the Medical Faculty Carl Gustav Carus Dresden, patients were recruited in three of the four psychiatric hospitals in the city of Dresden (population 460,000) in East Germany. Rather than creating diagnostic groups comparable in their most important socio-demographic and illness-related features, the sampling process was designed to recruit a casual sample from clinical reality. Therefore, on defined weekdays from October 2003 through August 2004, researchers contacted all potentially relevant patients (age range from 18 to 
65 years) with the designated main clinical ICD-10 diagnoses being treated in the inpatient and outpatient facilities of these hospitals. Researchers asked for consent to provide written materials about the research project to relatives/closest reference persons identified by the patient (note: patients with co-morbid neurological and severe medical disorders were excuded). Each relative met at least three of the following eligibility criteria (Perlick et al. 1999): parent or spouse/ partner or sibling or child of the patient, person providing the most frequent contacts with the patient, person who will be informed by the caring institution in case of any emergency, person assisting the patient in dealing with financial issues and person who most frequently accompanies the patient to medical treatments. For study inclusion the patient and at least one of the eligible relatives/closest reference persons provided written informed consent.

A total sample of 163 relatives of 158 patients with the diagnoses of schizophrenic (F20.x), recurrent depressive (F33.x) or bipolar disorders (F31.x) was recruited, with a refusal rate (for patients and relatives) of $12.3 \%$. Thus, the calculated "optimal" sample size of 50 patients in each diagnostic subgroup [in order to detect at least mean effect sizes of $\varepsilon \approx 0.30$ for the burden of relatives assessed with the Involvement Evaluation Questionnaire (Kallert 2002)] was exceeded. The clinical diagnosis was re-examined by an independent evaluator (for a detailed description of this procedure and its results, see Nitsche and Kallert 2007). A researcher (i.e., clinical psychologist) collected the data for this study using a standardized questionnaire completed during interviews with the relatives. The interview was conducted when the patient had been at home for a minimum of 4 weeks since the last inpatient or day hospital treatment (mean: 24.0 months; SD: 63.2 months; range: 4 weeks to 35 years). Furthermore, clinical charts of the patients included in the study were analyzed, focusing mainly on socio-demographic and illness-related data.

The mean age of the relatives was 50.1 years. Older adults represented the majority of this sample. Of the interviewees, $57 \%$ were female. Nearly two-thirds of the participants were spouses $(40.5 \%)$ or parents $(23.9 \%)$ of patients. On average relatives had supported the patient for 12 years (Table 1).

The mean age of the patients was 47.1 years, and $54 \%$ of the patients were female. The average time since the onset of their illness was approximately 15 years, and the patients had been hospitalized on average five times (Table 2).

\section{Measures}

\section{Outcome}

Psychological distress (PD) was assessed with the 12-item version of the General Health Questionnaire (GHQ) (Gold- berg 1978; Goldberg and Williams 1988; Goldberg et al. 1997; Donath 2000; Pevalin 2000). This self-rating instrument compares mental well-being within the previous 4 weeks with the preceding period, and aims to identify disruptions in the normal level of functioning regarding self-confidence, mental strain (concentration, anxiety, depression) and realization of duties in everyday life. Because the current study focused on the extent of PD, a 4-point Likert scale was used, and a total mean score of the 12 items was calculated. This produced a range of results from 0 (i.e., better than usual) to 3 [i.e. much less (or more) than usual]. A Cronbach's alpha of 0.88 showed sufficient internal consistency of the GHQ within the current study.

\section{Environmental variables}

A total of 62 environmental variables were subdivided into two blocks. Block 1 contained 37 patient-centered features covering socio-demographic characteristics and objective illness-related characteristics (e.g., main clinical diagnosis, co-morbidity). Both areas were assessed when analyzing the patients' clinical charts by use of the Client SocioDemographic and Clinical History Inventory (CSCHI) (Kallert et al. 2000). In addition, the psychiatrist in attendance assessed the patient's current psycho-social level of functioning with the Global Assessment of Functioning Scale (GAF) (Saß et al. 1998). Furthermore, whether and in which ways the patient received support from professional caregivers (nine items) were explored.

Block 2 of the environmental variables contained 25 features of the relatives, subdivided into two main areas. Socio-demographic features were recorded using the CSCHI. The relationship of the relative to the patient was classified as follows: blood relationship (child, parent, sibling), partnership (long-term or marriage), other (close friend, legally appointed care provider, etc.). Furthermore, we recorded whether the relative and patient had been living together in one household and the duration in number of hours per week on average of their personal contact in the previous four weeks.

Person variables

The 19 person variables, understood as personal traits and attitudes of relatives, were assigned to Block 3. In detail, we included:

The construct of sense of coherence (Antonovsky 1983), representing a relatively stable basic, enduring, though dynamic, feeling of confidence of an adult person to manage his or her own life in an active and healthpromoting way even in stressful situations. The current study used the 13-item version of the Sense of Coherence Scale (SOC) and included the sum score of all items in the 
Table 1 Socio-demographic and illness-related features of the patients $(\mathrm{N}=158$; sub-divided according to the three main diagnostic ICD-10 categories)

\begin{tabular}{|c|c|c|c|c|}
\hline & Schizophrenic disorders & Recurrent depressive disorders & Bipolar disorders & Total sample \\
\hline \multicolumn{5}{|l|}{ Gender } \\
\hline Female & 19 & 31 & 35 & 85 \\
\hline Male & 34 & 21 & 18 & 73 \\
\hline \multicolumn{5}{|l|}{ Age } \\
\hline \multicolumn{5}{|l|}{ In years } \\
\hline Mean & 44.4 & 49.4 & 47.6 & 47.1 \\
\hline SD & 14.8 & 11.8 & 14.8 & 13.9 \\
\hline \multicolumn{5}{|l|}{ Marital status } \\
\hline Married & 10 & 36 & 27 & 73 \\
\hline Divorced & 11 & 8 & 12 & 31 \\
\hline Widowed & 4 & 1 & 3 & 8 \\
\hline Single & 28 & 7 & 11 & 46 \\
\hline \multicolumn{5}{|l|}{ Co-morbid diagnosis } \\
\hline None & 15 & 11 & 17 & 43 \\
\hline Only psychiatric co-morbidity & 7 & 7 & 5 & 19 \\
\hline Only somatic co-morbidity & 20 & 10 & 17 & 47 \\
\hline Both & 11 & 24 & 14 & 49 \\
\hline \multicolumn{5}{|l|}{ Onset of the disorder } \\
\hline \multicolumn{5}{|l|}{ Years before study inclusion } \\
\hline Mean & 16.1 & 17.4 & 13.1 & 15.5 \\
\hline $\mathrm{SD}$ & 11.9 & 13.6 & 9.8 & 11.9 \\
\hline \multicolumn{5}{|l|}{ Time period at home } \\
\hline$<2$ months & 27 & 26 & 18 & 71 \\
\hline 2-6 months & 11 & 7 & 13 & 31 \\
\hline 6-12 months & 0 & 6 & 5 & 11 \\
\hline$>1$ year-5 years & 9 & 6 & 10 & 25 \\
\hline$>5$ years & 1 & 1 & 4 & 6 \\
\hline$>10$ years & 5 & 2 & 2 & 9 \\
\hline
\end{tabular}

Explanations: "time period at home" = period during which the patient has received community mental health care after the last hospitalization until the time point of the interview of his or her relative

analysis (Cronbach's alpha=0.82) (Antonovsky 1993; Schnyder et al. 2000; Schumacher et al. 2000; Nilsson et al. 2003).

The construct of mastery was established as a general control belief of the person to master important things in life with one's own resources. As an assessment instrument we used the 7-item Mastery Scale (MS) (Pearlin et al. 1981) and included the mean scale score in the analysis (Cronbach's alpha $=0.70$ ).

The general attitude of relatives towards mental disorders was explored with the German version of the standardized Questionnaire on the Opinions of the Family (QOF) (Magliano et al. 1999; Kallert and Nitsche 2008) (Cronbach's alpha of the subscales between 0.63 and 0.48 ).

Relatives' causal attributions of the causes of the mental disorders in the supported patients were assessed with the original Italian version of the QOF (Magliano et al. 1999).
The 14 items with an alternative response format, e.g., "assumed hereditary cause of disorder: yes-no," were transferred to the German QOF version.

Primary appraisal

Relatives assessed the "severity of the mental disorder of the supported person" directly (psychopathology) and indirectly (burden experienced, costs associated with providing support, prognosis). This assessment is represented by the 19 variables in Block 4:

For assessment of the patient's psychopathological symptoms by relatives we used the Positive and Negative Syndrome Scale (PANSS) (Kay et al. 1987; for detailed results of this procedure, see Nitsche and Kallert 2007). All six factors described by Nitsche and Kallert (2007) were included in the analysis: anergia, anxious-depressive con- 
Table 2 Socio-demographic and illness-related features of the relatives/close reference persons $(\mathrm{N}=163$; sub-divided according to the main diagnostic ICD-10 categories of the patients)

\begin{tabular}{|c|c|c|c|c|}
\hline & Schizophrenic disorders & Recurrent depressive disorders & Bipolar disorders & Total sample \\
\hline \multicolumn{5}{|l|}{ Gender } \\
\hline Female & 38 & 26 & 29 & 93 \\
\hline Male & 17 & 27 & 26 & 70 \\
\hline \multicolumn{5}{|l|}{ Age } \\
\hline \multicolumn{5}{|l|}{ In years } \\
\hline Mean & 55.7 & 47.9 & 46.6 & 50.1 \\
\hline $\mathrm{SD}$ & 14.9 & 13.9 & 13.6 & 14.6 \\
\hline \multicolumn{5}{|l|}{ Marital status } \\
\hline Married & 43 & 39 & 42 & 124 \\
\hline Divorced & 4 & 4 & 8 & 16 \\
\hline Widowed & 5 & 0 & 0 & 5 \\
\hline Single & 3 & 10 & 5 & 18 \\
\hline \multicolumn{5}{|l|}{ Education } \\
\hline Secondary school & 0 & 0 & 0 & 0 \\
\hline University entrance qualification & 33 & 35 & 36 & 104 \\
\hline Other & 21 & 17 & 19 & 57 \\
\hline \multicolumn{5}{|l|}{ Relationship to the patient } \\
\hline Parent & 30 & 2 & 7 & 39 \\
\hline Spouse/partner & 8 & 43 & 32 & 83 \\
\hline Sibling & 6 & 1 & 0 & 7 \\
\hline Child & 7 & 7 & 7 & 21 \\
\hline Other & 4 & 0 & 9 & 13 \\
\hline \multicolumn{5}{|l|}{ Closest reference person of the patient } \\
\hline Yes & 36 & 49 & 43 & 128 \\
\hline Partly & 18 & 2 & 11 & 31 \\
\hline No & 1 & 2 & 1 & 4 \\
\hline \multirow{2}{*}{\multicolumn{5}{|c|}{$\begin{array}{l}\text { Duration of support for the patient } \\
\text { In years }\end{array}$}} \\
\hline & & & & \\
\hline Mean & 12.3 & 12.2 & 10.2 & 11.6 \\
\hline SD & 9.6 & 11.5 & 9.5 & 10.2 \\
\hline
\end{tabular}

cern, delusional beliefs, cognitive impairments, motor impairments and problematic social behavior (Cronbach's alpha of the factors between 0.87 and 0.62 ; mean $=0.76$ ).

The burden experienced by the relatives caused by the patient's symptoms was assessed with the subscales "tension" and "worrying" of the Involvement Evaluation Questionnaire (IEQ). The IEQ (Schene et al. 1998; van Wijngaarden et al. 2000) assesses different areas of caregiving. The two aforementioned subscales represent interpersonal problems that are correlated with the severity of the mental disorder. "Tension" refers to the atmosphere between the caregiving relative and the patient; "worrying" assesses cognitions and activities of the caregiving relative concerning the safety, health and professional care of the patient. Internal consistency of the subscales in the current study is within an alpha range of 0.69 to 0.80 .
Depending on the severity of the disorder, relatives feel more or less obliged to carry extra expenses caused by the behavior or the disorder of the patient. These expenses are covered by the IEQ items 47 to 54 .

The need for alternate arrangements in the absence of the relative was assessed with the following question: "If you are absent for a longer period do you feel obliged to organize alternative care for the patient because he or she would not be capable of managing his or her own affairs otherwise?" This was answered in an alternative yes-no response format.

To explore the prognosis of the mental disorders, we asked the relatives: "Do you believe that the patient will be healthy again?" Responses were recorded on a 5-point Likert scale ranging from "yes, completely" $(=4)$ to "no, not at all" $(=0)$. 
Secondary appraisal

The assessment of resources needed to adequately cope with the mental disorder of the patient referred to two areas of variables. One area covered person variables about the relative (e.g., own illnesses, further critical life events). The second area of variables referred to the disorder of the supported patient such as subjective experience of relief provided by the use of other care options, time period of the support provided by the relative and position of the relative as closest reference person for the patient. Thus, Block 5 contained a total of $\mathbf{3 5}$ variables comprising the following details:

To assess illnesses of relatives, we administered a separate 14-item questionnaire (can be requested from the corresponding author).

To explore the relatives' time budget for their own activities and their worries about their own future that might influence their coping resources, we used two IEQ items. Item 36 addresses the ability to pursue one's own activities and interests during the previous 4 weeks with a 5 -step rating scale $[0=$ never, $4=$ (almost) always $]$. Using the same response format, item 42 assesses the extent of worry about one's own future during the previous 4 weeks.

For the assessment of critical life events during the previous 6 months (e.g., separation due to marital difficulties, major financial crisis), we used the List of Threatening Experiences (LTE) (Brugha et al. 1985; Brugha and Cragg 1990). In the current study, we analyzed the answers to each item separately. Furthermore, we calculated the sum of critical life events for each relative.

Four questions assessed the relief experienced attributed to professional care options used by the patient: (1) "Does the professional care in general provide relief for you as a relative?" and (2) “...for the patient?" The 4-step response scale for these two questions ranged from yes, strongly $(=3)$ to no, not at all $(=0)$. The other two questions in this area were: (3) "Do you think that the prescribed (psychopharmacological) medication provides help for the patient?" and (4) "...that the consultations with the psychiatrist provide help for the patient?" The response format for these two questions was a 5-step Likert scale ranging from: yes, absolutely (=4) to no, not at all $(=0)$.

\section{Coping}

Coping behavior of the relatives in relation to the mental disorder of the patients was assessed with the six variables included in Block 6:

The subscales "supervision" and "urging" of the IEQ represent aspects of the relatives' caregiving behavior. "Supervision" refers to the field of guarding and ensuring, e.g., making certain that he or she has taken required medication. "Urging" assesses the relatives' behavior and efforts to encourage and motivate the patient, e.g., to undertake some kind of activity. Internal consistency of the subscales in the current study is within an alpha-range of 0.62 to 0.71 .

IEQ items 44 and 45 ask about the extent to which the relative has become used to the patient having mental health problems, and the ability the relative feels to cope with the patient's mental health problems. For these self-assessments a 5 -step Likert scale $[0=$ no or never, $4=$ completely or (almost) always] was used.

Social control behavior of the relative concerning the patient and problems associated with this behavior were assessed with the Social Control Scale (SCS) (Stueve et al. 1997). The factorial structure given by these authors could not be replicated in the current study. Therefore, this paper provides the result of our own analysis (which can be requested from the corresponding author) extracting the factors "control requirement" and "control divergence" (Cronbach's alpha $=0.61$ and 0.63 ).

\section{Statistical analysis}

As the initial step, data were analyzed descriptively (calculation of absolute and relative frequencies, means and standard deviations). In addition, we performed an analysis of variance (ANOVA) to test for differences in the dependent variable (PD) between the three diagnostic groups.

To test the first hypothesis, bi-variate correlation analyses were calculated.

To test the second hypothesis we performed a process of developing a statistical model that comprised several stages. (1) Although a multivariate hierarchic regression analysis (blockwise inclusion of variables) established a sufficiently valid model for the total sample of relatives $\left(\mathrm{R}^{2}=0.54\right.$; can be requested from the corresponding author), this demonstrated severe disadvantages in respect to selection bias, insufficient model fit, inclusion of non-significant regressors and lack of non-linear relationships. (2) By use of stepwise model-building procedures (based on the variables identified in the correlation analyses), we therefore searched for the multiple linear regression model with the best possible model fit that must also demonstrate sufficient validity referred to the distribution of residue and the homogeneity of variances. This resulted in the model presented in the paper (including 35 original variables and 11 squared variables, and excluding 6 original variables because of too many missing values) because residue and QQ plots indicated superiority above other models. Further, this model makes use of all 163 datasets for the estimation of parameters, thus omitting any selection bias. (3) The seven co-variables definitely included in this optimal model 
were amended on a trial basis by each of ten variables (see results section) selected according to the results of the correlation analyses; this procedure is identical to the examination of partial correlations of each of the ten additional variables and the GHQ partialized according to the seven co-variables of the optimal model. This analysis used two variants of dealing with missing values: (a) all additional variables non-missing and (b) only the assessed variable non-missing. Variant (a) allows for a comparison of models by use of the Akaike information criterion; this is not possible for variant (b).

For the analysis we used the statistics programs SPSS for Windows, version 12.0, and SAS, version 9.

\section{Results}

Group differences in the extent of PD

Relatives of patients with recurrent depressive disorders (F33.x) evaluated the extent of their PD as the smallest (mean $=0.84 ; \mathrm{SD}=0.39$ ), whereas relatives of patients with bipolar disorders (F31.x) showed the greatest extent of PD (mean $=1.00, \mathrm{SD}=0.44)$. The GHQ mean of relatives of patients with schizophrenic disorders (F20.x) was 0.98 $(\mathrm{SD}=0.52)$, and thus closest to the mean $(0.94, \mathrm{SD}=0.46)$ of the total group of relatives. As a group, relatives tended to evaluate the extent of their PD within the previous 4 weeks, compared with the prior period, as the "same as usual" $(=1)$ or even slightly less.

Variance analysis of differences in the extent of PD among the three groups showed no statistically significant results $(\mathrm{F}=1.86, \mathrm{p}=0.16)$.

\section{Correlations between PD and the five areas of variables}

As shown in Table 3, at least two individual variables within each of the five areas of variables showed statistically significant correlations with PD for the complete group of 163 relatives. This confirms part one of the first hypothesis.

When the group of relatives was divided according to the three diagnostic subgroups of patients they are supporting, a statistically significant correlation between the GHQ and at least one individual variable in each area of variables appeared. It should be noted, however, that within the group of relatives supporting patients with recurrent depressive disorders, no significant correlation between the socio-demographic features of relatives (environmental variables-Block 2) and PD could be found. Thus, these results do not fully support the second part of hypothesis 1 .

Furthermore, Table 3 illustrates additional differences among the three diagnostic groups, including the proportion of significantly correlated variables of each block of variables and the type of variables. The highest number of variables significantly correlated with PD appeared within the group of relatives supporting a patient with a recurrent depressive disorder. Within Blocks 1 and 5 of the variables, further important differences appeared between the relatives of patients with schizophrenic disorders and the relatives of patients with affective disorders. Socio-demographic and illness-related features of the patients (Block 1) are more frequently correlated with $\mathrm{PD}$ in the groups supporting patients with affective disorders than in the group supporting patients with schizophrenia. In the sub-group of relatives supporting patients with schizophrenia, the majority of variables referring to the secondary appraisal processes (Block 5) that correlated with PD focused on the area of other critical life events. For the two other sub-groups of relatives, the majority could be found in the area of the relatives' own illnesses.

Consistently across all sub-groups of relatives, only four variables showed statistically significant correlations with PD: sense of coherence (SOC), mastery (MS), strained atmosphere between relatives and patients (IEQ sub-scale "tension") and concern of the relatives about their own future (IEQ item 42). These variables can be assigned to the areas of person variables and (primary and secondary) appraisal processes within the transactional stress model.

\section{Factors associated with relatives' psychological distress}

As shown in Table 4, the optimal model for factors influencing GHQ $\left(\mathrm{R}^{2}=0.58\right.$; adjusted $\left.\mathrm{R}^{2}=0.56\right)$ did include only seven variables. Firstly, among the environmental variables, only two patient variables-not including the diagnostic group - and none of the relatives' variables remained in the model indicating that the relatives' $\mathrm{PD}$ increases if the patient is of younger age and if the patient's duration at home since the last hospitalization is longer. Secondly, three person variables appeared as significant factors influencing the relatives' PD: it seems to be higher the lower the relative's sense of coherence and of mastery appears and if the relative assumes that alcohol is the cause of the patient's disorder. Thirdly, one of the primary appraisal variables seems to be significantly associated: the more the atmosphere between the caregiving relative and the patient is strained, the higher is the level of PD. Fourthly, also one of the secondary appraisal variables seems to be of importance: the higher the extent to which the relative is worried about his own future, the higher is the level of PD.

None of the tested additional ten variables (person variable: QOF-factor social distance; primary appraisal variables: IEQ subscale "worrying," PANSS factors anergia and motor impairments, and need for an arrangement in the 
Table 3 Features in each area of variables that correlated (alpha $\leq 0.05)$ with psychological distress of relatives (assessed with the GHQ)

\begin{tabular}{|c|c|c|c|c|}
\hline & $\begin{array}{l}\text { Total } \\
\text { sample }\end{array}$ & $\begin{array}{l}\text { Schizophrenic disorders } \\
\text { (F20.x) }\end{array}$ & $\begin{array}{l}\text { Recurrent depressive } \\
\text { disorders (F33.x) }\end{array}$ & $\begin{array}{l}\text { Bipolar disorders } \\
(\mathrm{F} 32 . \mathrm{x})\end{array}$ \\
\hline \multicolumn{5}{|l|}{ Environmental variables (patients) } \\
\hline Age & -0.18 & & -0.32 & -0.33 \\
\hline Children $^{\mathrm{a}}$ & & & -0.34 & \\
\hline Disability pension $^{\mathrm{a}}$ & & & .028 & \\
\hline Duration at home since last hospitalization & & 0.29 & & \\
\hline $\begin{array}{l}\text { Care provided by psychiatrist in private } \\
\text { practice }^{\mathrm{a}}\end{array}$ & 0.22 & & & 0.35 \\
\hline $\begin{array}{l}\text { Care provided by general physician in private } \\
\text { practice }^{\mathrm{a}}\end{array}$ & & & & -0.32 \\
\hline Environmental variables (relatives) & & -0.36 & & \\
\hline \multicolumn{5}{|l|}{$\operatorname{Sex}^{\mathrm{b}}$} \\
\hline Status as blood relative ${ }^{\mathrm{a}}$ & & & & 0.33 \\
\hline $\begin{array}{l}\text { Number of persons in household aged } \\
>65 \text { years }\end{array}$ & -0.18 & & & -0.35 \\
\hline Net income of the household & -0.19 & & & -0.33 \\
\hline Evaluation of the financial situation & -0.17 & & & \\
\hline \multicolumn{5}{|l|}{ Person variables } \\
\hline Sense of Coherence (SOC) & -0.60 & -0.61 & -0.63 & -0.61 \\
\hline Mastery (MS) & -0.49 & -0.49 & -0.40 & -0.52 \\
\hline QOF factor "social distance" & 0.19 & 0.30 & 0.33 & \\
\hline $\begin{array}{l}\text { QOF factor "optimizing resources for } \\
\text { treatment" }\end{array}$ & & & & 0.42 \\
\hline $\begin{array}{l}\text { Assumed cause of the disorder: magic/ } \\
\text { witchcraft }^{\mathrm{a}}\end{array}$ & & & & 0.29 \\
\hline $\begin{array}{l}\text { Assumed cause of the disorder: wrong } \\
\text { treatment }^{\mathrm{a}}\end{array}$ & & & & 0.37 \\
\hline Assumed cause of the disorder: alcohol ${ }^{\mathrm{a}}$ & & & -0.30 & \\
\hline \multicolumn{5}{|l|}{ Primary appraisal } \\
\hline IEQ subscale "tension" & 0.49 & 0.60 & 0.53 & 0.38 \\
\hline IEQ subscale "worrying" & 0.30 & & 0.50 & 0.27 \\
\hline IEQ item 48: costs of damage caused by $\mathrm{P}^{\mathrm{a}}$ & 0.23 & 0.40 & & \\
\hline IEQ item 53: other expenses for $\mathrm{P}^{\mathrm{a}}$ & & & 0.31 & \\
\hline $\begin{array}{l}\text { Need for an arrangement in the absence of } \\
\text { the relative } \mathrm{e}^{\mathrm{a}}\end{array}$ & 0.21 & & & \\
\hline PANSS factor 1 : anergia & 0.25 & & 0.34 & \\
\hline PANSS factor 2: anxious/depressive concern & & 0.29 & & \\
\hline PANSS factor 4: cognitive impairments & 0.24 & 0.27 & 0.34 & \\
\hline PANSS factor 5: motor impairments & 0.31 & & 0.47 & \\
\hline \multicolumn{5}{|l|}{ Secondary appraisal } \\
\hline $\begin{array}{l}\text { IEQ item 36: time budget for pursuing own } \\
\text { activities }\end{array}$ & -0.18 & & -0.28 & \\
\hline $\begin{array}{l}\text { IEQ item 42: worry about one's own } \\
\text { future }\end{array}$ & 0.52 & 0.54 & 0.57 & 0.45 \\
\hline LTE2: serious illness of close relative ${ }^{a}$ & & 0.29 & & \\
\hline $\begin{array}{l}\text { LTE4: death of close family friend or another } \\
\text { relative }^{\text {a }}\end{array}$ & & & & 0.30 \\
\hline LTE6: breaking off of a steady relationship ${ }^{a}$ & 0.17 & 0.28 & & \\
\hline LTE7: serious problem with a close person ${ }^{\mathrm{a}}$ & 0.16 & & & \\
\hline $\begin{array}{l}\text { LTE8: unemployment/unsuccessfully seeking } \\
\text { work }^{\mathrm{a}}\end{array}$ & 0.20 & 0.43 & & \\
\hline LTE sum score & 0.21 & 0.45 & & \\
\hline Own mental disorder ${ }^{\mathrm{a}}$ & 0.30 & & & \\
\hline Continuous treatment of own disorder ${ }^{\mathrm{a}}$ & & & 0.38 & 0.40 \\
\hline
\end{tabular}


Table 3 (continued)

\begin{tabular}{|c|c|c|c|c|}
\hline & $\begin{array}{l}\text { Total } \\
\text { sample }\end{array}$ & $\begin{array}{l}\text { Schizophrenic disorders } \\
\text { (F20.x) }\end{array}$ & $\begin{array}{l}\text { Recurrent depressive } \\
\text { disorders (F33.x) }\end{array}$ & $\begin{array}{l}\text { Bipolar disorders } \\
\text { (F32.x) }\end{array}$ \\
\hline Impairment caused by own disorder & 0.18 & & & 0.29 \\
\hline $\begin{array}{l}\text { Consequences of disorder: psycho-social } \\
\text { restrictions }^{\text {a }}\end{array}$ & 0.36 & & 0.60 & 0.37 \\
\hline Consequences of disorder: family problems ${ }^{\mathrm{a}}$ & & & 0.51 & 0.47 \\
\hline Consequences of disorder: none $\mathrm{a}^{\mathrm{a}}$ & -0.26 & & -0.48 & \\
\hline Correlation between the disorders of $\mathrm{R} \& \mathrm{P}^{\mathrm{a}}$ & 0.31 & 0.57 & & \\
\hline \multicolumn{5}{|l|}{ Coping } \\
\hline SCS factor "control divergence" & 0.25 & & 0.42 & \\
\hline IEQ subscale "urging" & 0.19 & & 0.34 & \\
\hline IEQ subscale "supervision" & 0.18 & & & 0.30 \\
\hline $\begin{array}{l}\text { IEQ item 45: able to cope with P's mental } \\
\text { health problems }\end{array}$ & -0.24 & -0.32 & -0.35 & \\
\hline
\end{tabular}

Explanations: ICD-10 diagnoses: F20.x: schizophrenic disorders; F33.x: recurrent depressive disorders; F31.x: bipolar disorders. "P" = patient; "R" = relative. Variables in bold demonstrate the highest and, in all groups, statistically significant correlations with the GHQ

a Alternative response format: $0=$ no or not indicated; $1=$ yes or indicated

b Alternative response format: $1=$ female; 2 = male

absence of the relative; secondary appraisal variables: own mental disorder and psycho-social restrictions as consequence of the disorder; coping variables: SCS factor control divergence and IEQ subscales "urging" and "supervision") showed a partial correlation that was significantly different from zero, thus showing no important influence on the relatives' $P D$.

Thus, these results do very much support hypotheses 2 in demonstrating the importance of primary appraisal and person variables for influencing PD within the model and in demonstrating the lack of importance of coping variables and of environmental variables concerning features of the relative by not including variables from these areas into the model.

\section{Discussion}

\section{Study limitations}

The current study is restricted to cross-sectional interviewing of relatives of people with mental disorders from the area of Dresden, the capital of the Eastern German State of Saxony. The sampling procedure was chosen to recruit from facilities in one geographic area a casual group of relatives currently caring for patients treated in a community mental health setting. In general, relatives belonged to the middle class living in an urban area. These characteristics of the study design imply limitations to generalizing our findings and provide only indications of the appraisal processes within the stress model of Lazarus and Folkman (1987). In particular, reappraisal processes could not be considered in our cross-sectional and exploratory design. It should be emphasized, however, that our research adds to previous studies, of which there are very few (Struening et al. 1995; Provencher et al. 2003) assessing PD as the outcome domain and analyzing all significant areas of influence of the theoretical stress models used in these studies. Therefore, our design provides the opportunity to increase evidence on the crucial protective factors for maintaining relatives' mental health. Results can only be discussed when adequately combined with findings from other studies, because theoretical assumptions of the stress process are, as a rule, very complex. In our study design, we focused on appraisal processes and person variables, whereas the representation of coping - the importance of which for PD has already been demonstrated by many authors (e.g., Pearlin et al. 1990; Magliano et al. 1995 and 2000; Chakrabarti and Gill 2002) — was limited. Because the mean duration of one interview lasted between $21 / 2$ and $3 \mathrm{~h}$, a classic questionnaire such as COPE (Carver et al. 1989) could not be used.

\section{Person variables}

Contrary to the assumptions grounded in the stress model, person variables appeared to be very important factors of influence for PD in our study. Among these, sense of coherence clearly surpassed other variables such as opinions and causal attributions of mental disorders. Therefore, the basic confidence of the person in his or her healthmaintenance efforts and the basic confidence in his or her own abilities for defining meaningfulness seem to be of great importance to minimizing or avoiding $\mathrm{PD}$ in 
Table 4 Multiple linear regression model of factors influencing PD

\begin{tabular}{|c|c|c|c|c|c|}
\hline Variable & Block & Parameter estimate & Standard error & t Value & $\mathrm{p}$ Value \\
\hline Intercept & & 2.665 & 0.240 & 11.06 & $<0.0001$ \\
\hline Age of the patient & 1 & -0.007 & 0.0018 & -3.97 & 0.0001 \\
\hline Duration at home since last hospitalization & 1 & 0.0009 & 0.00035 & 2.63 & 0.0095 \\
\hline Sense of coherence (SOC) & 3 & -0.016 & 0.0033 & -4.80 & $<0.0001$ \\
\hline Mastery (MS) & 3 & -0.182 & 0.049 & -3.71 & 0.0003 \\
\hline IEQ subscale "tension" & 4 & 0.199 & 0.063 & 3.15 & 0.0020 \\
\hline Assumed cause of the disorder: alcohol & 3 & -0.239 & 0.110 & -2.17 & 0.0316 \\
\hline IEQ item 42: worry about one's own future & 5 & 0.024 & 0.0062 & 3.88 & 0.0002 \\
\hline
\end{tabular}

burdensome situations. Riman and Udris (1998) have described the position of sense of coherence within the process of dealing with burdens: when adequately expressed it enables the person to develop preventive resources for coping including competence to act, physical fitness and social intelligence. These resources could be activated, if needed, and react - if successfully applied - by strengthening the sense of coherence via internal causal attributions. Furthermore, Rimann and Udris (1998) demonstrated highly significant correlations between several health indicators and the sense of coherence. By means of a path analysis, Sek and Pasikowski (2002) found that sense of coherence most strongly influences primary appraisal: the persons with a high sense of coherence evaluated stressors as burdensome, but also viewed these as a challenge and not as threatening, thus leading to active and health-maintaining styles of coping. Numerous studies in research areas distinct from psychiatry (e.g., Schnyder et al. 2000; Forbes 2001; Suominen et al. 2001) have demonstrated that sense of coherence is a strong predictor for mental health and mental well-being. Cederblad and Hansson (1996) confirmed this in a study on a clientele characterized by a range of manifest psychiatric symptoms, and not by specific diagnoses of mental disorders. To our knowledge, however, the current study is the first one clearly showing the protective function of high sense of coherence in relation to PD also for relatives supporting patients of different diagnostic groups of mental disorders.

Mastery seems to be of slightly less importance than sense of coherence, although both variables in the current study show a substantial positive statistical correlation $(\mathrm{r}=$ $0.53 ; \mathrm{p}<0.001)$. One possible explanation could be that this result confirms Antonovsky's (1987) assumption that meaningfulness is the central component of sense of coherence, but that without this motivating power, the cognitively formed components, comprehensibility and manageability, do not exert sustainable effects. Mastery represents the general control belief of persons and thus predominantly a function of cognition and not of motivation. This also applies to causal attributions referring to mental disorders, like the one showing an important influence in this study that alcohol is the cause of the patient's disorder. If meaningfulness is really the crucial component, however, this could only be assessed with the more detailed version of the SOC and by using other variables closely connected to the concept of identity. Because the subscale structure of the SOC frequently cannot be replicated, such analyses are not recommended for the 13-item version.

\section{Appraisal processes}

Contrary to our hypothesis, both appraisal processes made relevant contributions to the extent of $\mathrm{PD}$, but this was of minor statistical significance compared with the person variables discussed above. One reason for this finding could be that the sense of coherence strongly forms the appraisal processes, and thus makes relative the caregivers' specific situation of being confronted with the mental disorder of the patient. From this point of view, it could be concluded that a high sense of coherence seems to provide the opportunity to cope with objectively difficult situations in principle, and vice versa. Another explanation may be that this finding is an artifact of the study design, because the primary intention was to assess an everyday life situation. Therefore, at the time point of the interviews, patients were in a stage of their disorder when outpatient mental health care was sufficient. Comparative research in highly acute stages of the disorders would be needed to test the first explanation against the second provided here.

Within the appraisal processes, features of primary appraisal are more clearly represented than those of secondary appraisal, particularly in the groups of relatives supporting patients with schizophrenic and recurrent depressive disorders. In accordance with the results of Schene et al. (1998), interpersonal problems covered by the IEQsubscale "tension" that might be viewed as indicators for the severity of the disorder provided a contribution for predicting PD. Harvey et al. (2001) also demonstrated the significance of negatively evaluating the caregiving relationship for PD. 
Therefore, it can be concluded that the extent of interpersonal problems experienced between relatives and patients influences PD via an immanent emotional component. This would also explain why the assessment of psychopathology by the relatives (PANSS factors) does not significantly influence PD. This assessment clearly focused on the mentally ill person, and only PANSS factor 6, "problematic social behavior," contains an element of the interaction between the caregiver and the patient. The variance of ratings on factor $6(\mathrm{SD}=0.61)$ is rather small (compared, for example, to factor 1, "anergia": $\mathrm{SD}=1.02$ ), however. Again, this could be attributed to the time point of assessment, which might restrict the ability of this "interpersonal" PANSS factor to influence PD. For future research, we recommend a more detailed assessment of the subjective meaning of critical life events and of the social support experienced within the area of secondary appraisal processes. This might enhance the importance of this area of variables.

At first glance, it seems somewhat surprising that the variables referring to the relatives' own illnesses do not influence PD, although these include the subjective experience of symptoms. This result gains plausibility, however, if we consider that none of the GHQ values of the assessed groups of relatives are within the critical range (mean $\leq 1)$ that would indicate impairment of general mental wellbeing. The result that the extent to which the relative is worried about his own future is of significant importance for the level of PD indicates, however, that the relative's subjective experience of feeling existentially endangered by taking care of chronically mentally ill should not be underestimated.

\section{Environmental variables and coping}

In concordance with results of research already cited, the current study demonstrated the minor importance of environmental variables for PD when subjective processes (e.g., individual appraisal, coping styles) or personal traits are included in the analysis. Only the age of the supported patient had significant influence on PD for the total group of 163 relatives. As already outlined, PD increased as the age of the patient decreased. Relatives of older patients might have gone through adaptation processes such as decreasing their level of demands and expectations. Furthermore, it seems reasonable that those individuals caring for younger patients more strongly take into account the life perspective of their relatives. In view of imminent or past professional, social and family-related restrictions imposed by the mental disorder in relation to the patient's lifetime, PD might increase; such perspective provides also a reasonable explanation for the importance of the patient's duration at home since the last hospitalization for the relative's PD.
Although the correlation analysis revealed some differences in the number and content of variables that might be relevant for exerting diagnostic group-specific influence on a relative's PD, such an effect did not appear in the developed statistical model for the whole group of relatives. This result is well in accordance with findings of numerous studies having demonstrated that it is not the diagnosis per se that is burdensome for relatives (summarized in Jungbauer 2005).

\section{Conclusions}

The results of our study enhance the validity of the transactional stress model demonstrating the influence of salutogenetic concepts (e.g., sense of coherence) more clearly than expected. Therefore, professional support of relatives of people with mental disorders should especially address relatives' competences and the increase in their own sense of personal growth. Further longitudinal studies are needed in order to analyze procedural aspects of appraisal processes and their impact on other areas of variables included in the stress model assessed in this study.

Acknowledgements The study, "Psychosocial burden and attitudes to disorders of relatives of chronically mentally ill persons-A comparison between schizophrenic and affective disorders especially taking into account socially disintegrating courses of the disorders and direct costs of community treatment," was supported by a grant (KA 1544/2-1 and 2-2) from the German Research Association (DFG).

We thank our colleagues in the three participating psychiatric hospitals (University Hospital of the Dresden University of Technology, St. Mary's Hospital Dresden-Klotzsche and Hospital Dresden-Neustadt) for their excellent cooperation.

We gratefully acknowledge the assistance in translation by Charlene Reiss.

Conflict of interest The authors disclose any relevant association that might pose a conflict of interest.

Conflict of interest statement There is no conflict of interest involved in conducting this study.

\section{References}

Antonovsky A (1983) The sense of coherence: development of a research instrument. In: Schwartz WS (ed) Newsletters and research reports 2. Research Center for Behavioral Medicine, Tel Aviv University, pp 1-11

Antonovsky A (1987) Unraveling the mystery of health. How people manage stress and stay well. Jossey-Bass Publishers, San Francisco

Antonovsky A (1993) The structure and properties of the Sense of Coherence Scale. Soc Sci Med 36:725-733

Boye B, Bentsen H, Ulstein I, Notland TH, Lersbryggen A, Lingjærde O, Malt UF (2001) Relatives' distress and patients' symptoms 
and behaviors: a prospective study of patients with schizophrenia and their relatives. Acta Psychiatr Scand 104:42-50

Brugha TS, Cragg D (1990) The List of Threatening Experiences: the reliability and validity of a brief life events questionnaire. Acta Psychiatr Scand 82:77-81

Brugha TS, Bebbington P, Tennant C, Hurry J (1985) The list of threatening experiences: a subset of 12 life event categories with considerable long-term contextual threat. Psychol Med 15:189 194

Carver CS, Scheier MF, Weintraub JK (1989) Assessing coping strategies: a theoretically based approach. J Pers Soc Psychol $56: 267-283$

Cederblad M, Hansson K (1996) Sense of coherence - a concept influencing health and quality of life in a Swedish psychiatric atrisk group. Isr J Med Sci 32:194-199

Chakrabarti S, Gill S (2002) Coping and its correlates among caregivers of patients with bipolar disorder: a preliminary study. Bipolar Disorders 4:50-60

Donath S (2000) The validity of the 12-item General Health Questionnaire in Australia: a comparison between three scoring methods. Austr N Z J Psychiatry 35:231-235

Forbes DA (2001) Enhancing mastery and sense of coherence: important determinants of health in older adults. Geriatr Nurs 22:29-32

Goldberg D (1978) The 12-item General Health Questionnaire (GHQ-12). NFER-Nelson, Windsor

Goldberg D, Williams P (1988) A user's guide to the General Health Questionnaire. NFER-Nelson, Windsor

Goldberg D, Gater R, Sartorius N, Ustun TB, Piccinelli M, Gureje O, Rutter C (1997) The validity of two versions of the GHQ in the WHO study of mental illness in general health care. Psychol Med 27:191-197

Harvey K, Burns T, Fahy T, Manley C, Tattan T (2001) Relatives of patients with severe psychotic illness: factors that influence appraisal of caregiving and psychological distress. Soc Psychiatry Psychiatr Epidemiol 36:456-461

Jacobi F, Klose M, Wittchen HU (2004) Psychische Störungen in der deutschen Allgemeinbevölkerung: Inanspruchnahme von Gesundheitsleistungen und Ausfalltage. Bundesgesundheitsbl Gesundheitsforsch - Gesundheitsschutz 47:736-744

Jenkins JH, Schumacher JG (1999) Family burden of schizophrenia and depressive illness. Specifying the effects of ethnicity, gender and social ecology. Br J Psychiatry 174:31-38

Jungbauer J (2005) Unser Leben ist jetzt anders. Belastungen und Belastungsfolgen bei Angehörigen schizophrener Patienten. Psychiatrie-Verlag, Bonn

Kallert TW (2002) Psychosocial burden and attitudes to disorders of relatives of chronically mentally ill persons - A comparison between schizophrenic and affective disorders especially taking into account socially disintegrating courses of the disorders and direct costs of community treatment. Research project funded by the German Research Association. http://www.dfg.de/gepris

Kallert TW, Nitsche I (2008) Assessing the opinions of relatives on the causes and social consequences of different mental disorders: are instruments cross-culturally valid? Psychiat Res 158:344-355

Kallert TW, Schützwohl M, Matthes C, Eden Study Group (2000) The Client Socio-Demographic and Clinical History Inventory. Medizinische Fakultät TU Dresden

Kay SR, Fiszbein A, Opler LA (1987) The Positive and Negative Syndrome Scale (PANSS) for schizophrenia. Schizophr Bull 13:261-276

Lazarus RS, Folkman S (1987) Transactional theory and research on emotions and coping. Eur J Personality 1:141-169

Magliano L, Veltro F, Guarneri M, Marasco C (1995) Clinical and socio-demographic correlates of coping strategies in relatives of schizophrenic patients. Eur Psychiatry 10:155-158
Magliano L, Marasco C, Guarneri M, Malangone C, Lacrimini G, Zanus P, Maj M (1999) A new questionnaire assessing the opinions of the relatives of patients with schizophrenia on the causes and social consequences of the disorder: reliability and validity. Eur Psychiatry 14:71-75

Magliano L, Fadden G, Economou M, Held T, Xavier M, Guarneri M, Malangone C, Marasco C, Maj M (2000) Family burden and coping strategies in schizophrenia: 1-year follow-up data from the BIOMED I study. Soc Psychiatry Psychiatr Epidemiol 35:109-115

Mueser KT, Webb C, Pfeiffer M, Gladis M, Levinson DF (1996) Family burden of schizo-phrenia and bipolar disorder: perceptions of relatives and professionals. Psychiatr Serv 47:507-511

Nilsson B, Holmgren L, Stegmayr B, Westman G (2003) Sense of coherence - stability over time and relation to health, disease, and psychosocial changes in a general population: a longitudinal study. Scand J Pub Health 31:297-304

Nitsche I, Kallert TW (2007) Standardized assessment of psychopathology by relatives of mentally disordered patients. Using the Positive and Negative Syndrome Scale (PANSS) to compare schizophrenic and affective disorders. Psychopathology 40:242-253

Pearlin LI, Menaghan EG, Lieberman MA, Mullan JT (1981) The stress process. J Health Soc Behavior 22:337-356

Pearlin LI, Mullan JT, Semple SJ, Skaff MM (1990) Caregiving and the stress process: an overview of concepts and their measures. Gerontologist 30:583-594

Perlick D, Clarkin JF, Sirey J, Raue P, Greenfield S et al (1999) Burden experienced by care-givers of persons with bipolar affective disorder. Br J Psychiatry 175:56-62

Pevalin DJ (2000) Multiple applications of the GHQ-12 in a general population sample: an investigation of long-term retest effects. Soc Psychiatry Psychiatr Epidemiol 35:508-512

Provencher HL,Fournier J-P, Perreault M, Vezina J (2000) The caregiver's perception of behavioral disturbance in relatives with schizophrenia: a stress-coping approach. Comm Ment Health J 36:293-306

Provencher HL, Perreault M, St-Onge M, Rousseau M (2003) Predictors of psychological distress in family caregivers of persons with psychiatric disabilities. J Psychiatr Mental Health Nursing 10:592-607

Rider SH (2004) Psychological distress: concept analysis. J Advanced Nursing 45:536-545

Rimann M, Udris I (1998) "Kohärenzerleben" (Sense of coherence): Zentraler Bestandteil von Gesundheit oder Gesundheitsressource? In: Schüffel W, Brucks U, Johnen R, Köllner V, Lamprecht F, Schnyder U (eds) Handbuch der Salutogenese. Konzept und Praxis. Ullstein Medical Verlagsgesellschaft $\mathrm{mbH} \& \mathrm{Co}$, Wiesbaden, pp 351-364

Saß H, Wittchen HU, Zaudig M (1998) Diagnostisches und Statistisches Manual Psychischer Störungen DSM-IV. Hogrefe, Göttingen Bern Toronto

Schene AH, van Wijngaarden B, Koeter MWJ (1998) Family caregiving in schizophrenia: domains and distress. Schizophr Bull 24:609-618

Schmid R, Huttel GU, Cording C, Spieß1 H (2007) Belastungen von Angehörigen mit bipolaren affektiven Störungen in stationärer Behandlung. Psychiat Prax 34:S155-S157

Schnyder U, Büchi S, Sensky T, Klaghofer R (2000) Antonovsky's sense of coherence: trait or state? Psychother Psychosom 69:296302

Schumacher J, Wilz G, Gunzelmann T, Brähler E (2000) Antonovsky's Sense of coherence Scale - Its validation in a populationbased sample and the development of a new short scale. Psychotherapie, Psychosomatik Med Psychologie 50:472-482 
Sek H, Pasikowski T (2002) Stressbewältigung im Rahmen der Salutogenese. In: Schumacher J (ed) Mensch unter Belastung. Erkenntnisfortschritte und Anwendungsperspektiven der Stressforschung. Verlag für Akademische Schriften, Frankfurt/M, pp $20-43$

Struening EL, Stueve A, Vine P, Kreisman DE, Link BG, Herman DB (1995) Factors associated with grief and depressive symptoms in caregivers of people with serious mental illness. Res Comm Ment Health 8:91-124

Stueve A, Vine P, Struening EL (1997) Perceived burden among caregivers of adults with serious mental illness: comparison of black, Hispanic, and white families. Am J Orthopsychiatry 67:199-209

Suominen S, Helenius H, Blomberg H, Uutela A, Koskenvuo M (2001) Sense of coherence as a predictor of subjective state health: results of 4 years of follow-up of adults. J Psychosom Res 50:77-86

van Wijngaarden B, Schene AH, Koeter MWJ, Vázquez-Barquero JL, Knudsen HC, Lasalvia A, McCrone P, EPSILON Study Group (2000) Caregiving in Schizophrenia: development, internal consistency and reliability of the Involvement Evaluation Questionnaire - European Version. EPSILON Study 4. Brit J Psychiatry 177(suppl. 39):21-27 